\title{
Injustiça na justiça do nazismo Relatos de sobreviventes da rosa branca
}

\author{
Janaina Lopes Salgado e Tinka Reichmann*
}

\section{Introdução}

Com a ascensão do nazismo em 1933 iniciou-se uma série de medidas legais, como promulgações de leis e a criação de tribunais especiais políticos, com a finalidade de garantir legalmente sua manutenção e expansão. Para exemplificar essa instrumentalização do sistema ${ }^{1}$ jurídico nazista e suas consequências no pós-guerra, destacaremos neste artigo a história de duas de suas vítimas políticas, Hans Hirzel e Franz Müller, ex-integrantes do grupo de resistência antinazista conhecido como Rosa Branca [Die Weiße Rose].

As ações do grupo, formado principalmente por universitários de Munique, consistiram na redação e distribuição de seis panfletos entre 1942 e 1943, nos quais denunciavam as atrocidades cometidas pelo regime nazista e convocavam a população à resistência. Hirzel e Müller, ambos com 19 anos na época, auxiliaram na distribuição de panfletos na cidade de Ulm. Na primeira sentença proferida pelo "Tribunal do Povo" nazista (Volksgerichtshof) em 22/02/1943, os irmãos Sophie e Hans Scholl e seu amigo Christoph Probst foram condenados à morte e executados no mesmo dia. Em 19/04/1943, na segunda sentença contra o grupo, Hirzel e Müller foram condenados juntamente com outros 12 integrantes do grupo ${ }^{2}$.

\footnotetext{
* Bacharel e licenciada em Letras (Alemão e Português) pela Universidade de São Paulo, onde cursa pós-graduação em tradução.

${ }^{1}$ Entendemos "sistema" como um conceito que abrange tanto as instâncias de poder quanto as instituições jurídicas e os operadores do direito.

2 Sobre a história da Rosa Branca e suas atividades de resistência, cf. a tradução brasileira A Rosa Branca (Scholl, 2014) e a dissertação de mestrado sob o titulo Quando a história (re)conta a história: análise textual e tradução comentada de interrogatórios da "Rosa Branca" (Schäfer, 2015), na qual encontra-se a tradução comentada dos protocolos dos interrogatórios de Sophie e Hans Scholl à Gestapo.
} 
Quase 40 anos após sua condenação, Müller deparou-se com a incerteza quanto à sua situação legal frente ao Judiciário do pós-guerra, incitado pelo lançamento do filme Die Weiße Rose (Verhoeven, 1982). A fim de esclarecê-la, escreveu para a Secretaria de Justiça do Estado Federado de Baden-Württemberg (SJ-BW), cuja resposta em 1983 mostrou-se tão ambígua quanto sua situação, demonstrando a não resolução em relação à vigência de condenações de vítimas políticas dos tribunais nazistas na Alemanha da década de 1980 .

\begin{abstract}
Visto que a sentença do Tribunal do Povo proferida contra o senhor não se encontra em nossas mãos no momento, não nos encontramos em condições de nos pronunciarmos sobre a validade ou invalidade da sentença do Tribunal do Povo proferida contra o senhor. [...] Visto que o prazo de requerimento já expirou, então teríamos que partir do princípio de que a decisão continua sendo válida. ${ }^{3}$ (SJ-BW, p. 2, tradução nossa)
\end{abstract}

Frente à inexistência de uma lei federal de anulação das sentenças nazistas à época, poder-se-ia considerar Müller condenado ou não, dependendo do estado ao qual essa informação fosse solicitada. No ano seguinte, em 14/03/1984, ocorreu a $17^{a}$ sessão do Parlamento Alemão para a qual Müller e Hirzel, ambos formados em direito, foram convidados a depor sobre as práticas jurídicas nazistas. Trata-se da primeira de inúmeras sessões parlamentares após 1945 relativas à necessidade de correção da injustiça praticada pelo Judiciário nazista, somente concretizada com a promulgação em 1998 da "Lei de revogação das sentenças penais da Injustiça extrema nazista na aplicação da justiça penal (LA-NS)" ${ }^{4}$, cujo texto anulou retroativamente as sentenças penais nazistas.

Nesse contexto, o presente artigo apresentará um estudo em andamento do contexto de tradução do conceito alemão Unrecht a partir de fragmentos dos depoimentos de Müller e Hirzel no Parlamento Alemão. Em alemão, o prefixo "un-" pode modificar o substantivo não somente no sen-

\footnotetext{
${ }^{3}$ Da uns das gegen Sie ergangene Urteil des Volksgerichtshofs nicht vorliegt, sehen wir uns nicht in der Lage, eine verbindliche Aussage bezüglich der Gültigkeit oder Ungültigkeit des Sie betreffenden Volksgerichtshofsurteils zu machen. [...] Da die Antragsfrist bereits abgelaufen ist, wäre dann davon auszugehen, daß die Entscheidung nach wie vor gültig ist.

${ }^{4}$ Gesetz zur Aufhebung nationalsozialistischer Unrechtsurteile in der Strafrechtspflege (NS-AufhG).
} 
tido de sua negação, como Glück/Unglück, (sorte/azar), mas também transformá-lo semanticamente num aumentativo, como Summe/Unsumme (valor/valor altíssimo) ou, de outra forma, como Mut/Unmut (coragem/indignação). O vocábulo Unrecht (literalmente: "não-direito") desenvolveu, em alemão, um significado muito complexo que necessita ser estudado em seu contexto específico antes de qualquer tentativa de tradução. $\mathrm{O}$ dicionário DUDEN apresenta os seguintes significados de Unrecht: a) princípio que é oposto ao direito, à justiça; princípio que nega o direito, a justiça; b) comportamento, ação, ato considerado injusto; c) situação ou fato considerado como perturbação da ordem jurídica ou moral (tradução nossa) $)^{5}$.

Das 64 páginas do protocolo, restringimo-nos às 27 páginas iniciais, nas quais se encontram os depoimentos, por concentrarem o cerne do debate acerca da invalidade do sistema jurídico nazista e suas práticas que levou, entre outros, à promulgação da lei de revogação de 1998, bem como referências importantes à compreensão do estado de injustiça extrema [Unrecht] durante o nazismo, termo alemão recorrente em todo o documento e colocado constantemente em oposição a uma noção de justiça considerada como um direito verdadeiro pelos depoentes, como demonstraremos na seção 2 desse artigo.

O documento em questão não se encontra disponível ao público geral até mesmo na Alemanha. Trata-se de um material arquivado no Parlamento Alemão em Berlim, cujo acesso somente foi possível após uma autorização especial concedida em 2011 à Prof ${ }^{\mathrm{a}}$ Dr $^{\mathrm{a}}$ Tinka Reichmann para realizar pesquisas bibliográficas para o projeto de tradução do livro $A$ Rosa Branca (Scholl, 2013). Devido à não disponibilização ao acesso público na Alemanha, esse documento não possui tradução para o português, portanto, sua tradução oferecerá novas fontes de pesquisa às áreas de História e Direito concernentes aos períodos de justiças transicionais.

\footnotetext{
${ }^{5}$ a) dem Recht, der Gerechtigkeit entgegengesetztes, das Recht, die Gerechtigkeit verneinendes Prinzip; $[\ldots]$ b) als unrecht empfundene Verhaltensweise, Handlung, Tat [...], als Störung der rechtlichen oder sittlichen Ordnung empfundener Zustand, Sachverhalt. (DUDEN, 2006, p. 1769)
} 


\title{
2. O sistema jurídico nazista e o pós-guerra
}

Como parte do estudo do conceito de Unrecht, delinearemos nessa seção alguns aspectos relevantes do período nazista relacionados às modificações do sistema jurídico nesse período e seus reflexos no Pós-guerra. Após a nomeação de Hitler ao cargo de chanceler em 1933, a propaganda e o governo empenharam-se, entre outras medidas, em assegurar legalmente suas ações que se tornavam gradativamente mais radicais, principalmente, próximo ao final da guerra. No campo jurídico, foram promulgados "mais de setecentos decretos e leis" (Hudemann, 2014, p. 242), "uma avalanche de leis e decretos", nas palavras de Arendt (1989, p. 444). A autora ainda acrescenta:

\begin{abstract}
A ascensão de Hitler ao poder foi legal dentro do sistema majoritário, e ele não poderia ter mantido a liderança de tão grande população, sobrevivido a tantas crises internas e externas, e enfrentado tantos perigos de lutas intrapartidárias, se não tivesse contado com a confiança das massas. (Arendt, 1989, p. 356)
\end{abstract}

Stolleis (1994, p. 18-19) confirma as inúmeras mudanças políticas com reflexo na área jurídica, subjugando paulatinamente qualquer instância jurídica ou política às vontades do Führer, como sua ascensão aos cargos de presidente e chanceler, a centralização do poder em seu partido (o $\mathrm{NSDAP}^{6}$ ), eliminando qualquer possibilidade de oposição e controle do Estado, a ocupação de cargos importantes do executivo por membros do partido etc., culminando na militarização:

\footnotetext{
Por meio do terror provisoriamente legalizado e de pressão política, os partidos dissolveram-se. O NSDAP tornou-se um partido centralizado. [...] No fim, restou um estado centralizado militarizado e autoritário que procurou sobrepujar os conflitos de interesses por meio da propagação potente de um "pensamento de comunidade". ${ }^{7}$ (Stolleis, 1994, p. 18-19, tradução nossa)
}

\footnotetext{
${ }^{6}$ Nationalsozialistische Deutsche Arbeiterpartei (Partido Nacional-Socialista dos Trabalhadores Alemães).

${ }^{7}$ Durch notdürftig legalisierten Terror und politischen Druck lösten sich die Parteien auf. Die NSDAP wurde Staatspartei. [...] Am Ende stand ein militarisierter autoritärer Einheitsstaat, der die Interessengegensätze durch lautstarke Propagierung eines „Gemeinschaftsdenkens“ zu überspielen suchte.
} 
Quaisquer formas de oposição ou resistência ao regime estavam suscetíveis a duras condenações, toda a população estava passível de se tornar suspeita de um crime ${ }^{8}$. Um dos principais instrumentos nazistas para sufocar gradualmente quaisquer manifestações de resistência ou oposição foi o "Tribunal do Povo" [Volksgerichtshof], criado pelo regime por meio de uma lei ${ }^{9}$ em resposta ao resultado insatisfatório (do ponto de vista do regime) do processo sobre o incêndio do Parlamento Alemão (Reichstagsbrand), em 27/02/1933. Essa lei também implantou determinações penais mais severas com relação aos crimes de "alta traição" (Hochverrat) e "traição do país" (Landesverrat) (Schmitz-Berning, 2000, p. 665) os quais, juntamente com os crimes de "favorecimento do inimigo" (Feindbegünstigung) e "corrupção do poderio militar" (Wehrkraftzersetzung), faziam parte das acusações mais comuns contra réus políticos de tribunais nazistas, como os integrantes do grupo de resistência Rosa Branca.

Também Rätsch (1992), Haft (2009), Hillermeier (1980), entre outros, apontam para a promulgação de inúmeras leis e decretos. Ainda afirmam que, ao lado dos "Tribunais Especiais Políticos" (Sondergerichte) - também criados pelo regime -, o "Tribunal do Povo" foi o principal instrumento de aplicação dessas leis, recebendo posteriormente a alcunha "instrumento de terror" (Haft, 2009). Ademais, os direitos dos réus não existiam (Rätsch, 1992, p. 17).

Segundo Zarusky (1994, p. 676), o que impulsionava e orientava os processos do "Tribunal do Povo" era a frequente manipulação da imagem dos réus como "inimigos do Reich", uma vez que "não havia maneira mais eficaz de propagar a pretensão de domínio mundial dos nacionalsocialistas do que punir como alta traição qualquer pronunciamento ou ato contra o Terceiro Reich, não importa quando, onde ou por quem fosse feito" (Arendt, 1989, p. 466). Trata-se da identificação e revelação dos "inimigos objetivos" (Arendt, 1989, p. 474-475) do nazismo, assemelhando-se à

\footnotetext{
8 Arendt (1989, p. 481) aponta que "nas condições do regime totalitário, a categoria dos suspeitos compreende toda a população; todo pensamento que se desvia da linha oficialmente prescrita e permanentemente mutável já é suspeito, não importa o campo de atividade humana em que ocorra".

9 Gesetz zur Änderung des Strafrechts und des Strafverfahrens vom 24. April 1934. Disponível em: <http://www.documentarchiv.de/ns/1933/stgb-landes-hochverrat-volksgerichtshof_ges.html>. Acesso em: 12 de ago. 2016.
} 
postura de Hitler que utilizava frequentemente a "acusação como instrumento para instigar seres humanos a formarem uma massa" (Canetti, 2011, p. 190) contra tais inimigos, enquanto a polícia atuava como executora ${ }^{10}$. Portanto, "não podemos desconsiderar o poder que as palavras têm de interferir na realidade, impondo uma visão de mundo preconceituosa, autoritária" (Carneiro, 2012, p. 263) e diríamos até mesmo excludente ao identificar constantemente os réus à imagem de "inimigos do Povo" e não do governo totalitário.

Quanto à punição, Silva (2008, p. 91, grifo nosso) pontua que ela "não é só uma sanção derivada da repressão, mas tem uma função social; $a$ punição não provém das regras do direito, mas é um entre outros procedimentos de poder existentes em táticas políticas [...]". Tal instrumentalização da punição está em consonância com o fato de que muitos réus de tribunais nazistas eram até mesmo executados a guisa de exemplo para intimidação geral - como foi o caso do núcleo da Rosa Branca -, de que a aplicação das penas era maleável e imprevisível e de que as decisões podiam converter-se em quaisquer outras penalidades.

Dentro desse contexto totalitário ${ }^{11}$, apesar da intensa repressão e eliminação sistemática de opositores políticos, surgiram diversos grupos e movimentos de resistência antinazista. Um dos mais simbólicos é retratado no filme Die weiße Rose (Verhoeven, 1982), no qual conta-se a história do grupo cujos principais integrantes foram identificados, presos pela Gestapo (polícia secreta alemã) e condenados à morte nos dois únicos julgamentos contra o grupo, proferidos pelo "Tribunal do Povo", sob a presidência do juiz Roland Freisler ${ }^{12}$. Assim, como constata Arendt (1989, p. 484), ao versar

\footnotetext{
10 Segundo Arendt (1989, p. 476), “o dever da polícia totalitária não é descobrir crimes, mas estar disponível quando o governo decide aprisionar ou liquidar certa categoria da população".

${ }^{11}$ Entendemos o conceito de totalitarismo assim como definido por Arendt (1989, p. 469-470), segundo o qual "o partido governante não tolera outros partidos nem oposição, nem admite a liberdade de opinião política [...] o totalitarismo no poder usa o Estado como fachada externa para representar o país perante o mundo não-totalitário". Além disso, há uma interdependência entre as massas e o líder totalitário que as governa, sendo que este "impõe o seu pensamento e o seu desejo sobre um grupo destituído de pensamento e de vontade - seja por meio da persuasão, da autoridade, ou da violência", garantindo um domínio "permanente de todos os indivíduos em toda e qualquer esfera da vida" (Arendt, 1989, p. 375). 12 Em sua carta de agradecimento pela nomeação ao cargo, Freisler, "soldado político" de Hitler, reafirma sua submissão, independente de questões legais: Meu Führer! [...] o mais supremo senhor da Justiça e juiz do Povo alemão, responsável pela jurisprudência do seu tribunal político mais elevado. O
} 
sobre as atividades da polícia secreta russa, os "crimes" de acusados investigados por governos totalitários são determinados “'objetivamente' antes mesmo de serem presos".

Segundo relatos sobre a atuação do "Tribunal do Povo" (Hillermeier, 1980; Rätsch, 1992; Zarusky; 1994) e a história da Rosa Branca, suas condenações foram uma das medidas extremas empregadas pelo regime para a intimidação geral, de modo que as três sentenças de morte proferidas no primeiro processo contra os irmãos Scholl e Probst foram executadas no mesmo dia, em 22/02/1943.

Mesmo para os padrões arbitrários da época, a execução sumária da sentença, bem como o deslocamento integral do "Tribunal do Povo" de sua sede em Berlim para julgar o caso em Munique, demonstram a grande apreensão do regime com relação às ações do grupo, considerando-se que "a resistência [...] podia provocar em Hitler uma fúria extrema" (Canetti, 2011, p. 195). Tratava-se de uma mensagem contundente a qualquer opositor quanto ao poder do regime, pois "se a legalidade é a essência do governo não tirânico e a ilegalidade é a essência da tirania, então o terror é a essência do domínio tirânico" (Arendt, 1989, p. 517).

O breve panorama aqui traçado apresentou alguns dos acontecimentos durante o nazismo que ilustram a instrumentalização de seu sistema jurídico em prol da manutenção do regime, cujos resquícios permaneceram mesmo no período subsequente ao final da guerra. Entretanto, houve um empenho nos anos do pós-guerra em reconstituir a democracia na Alemanha, também de modo a se opor a uma visão comum fora do país de que "o nacional-socialismo teria sido a expressão da própria 'alma alemã', a consequência de uma mentalidade de obediência servil aos dirigentes que seria parte do 'caráter do povo alemão'" (Hudemann, 2014, p. 252). Hudemann (ibid., p. 253) também pontua que "muitas vezes não era fácil separar claramente os 'papéis' de perpetrador e de vítima".

Tribunal do Povo esforçar-se-á sempre para assim julgar como ele achar que o senhor mesmo, meu Führer, julgaria o caso. Heil, meu Führer! Com lealdade, seu soldado político, Roland Freisler." (Buchheit apud Rätsch, 1992, p. 16, tradução nossa) [Mein Führer! [...] dem Obersten Gerichtsherrn und Richter des deutschen Volkes, für die Rechtsprechung Ihres höchsten politischen Gerichtes verantwortlich zu sein. Der Volksgerichtshof wird sich stets bemühen, so zu urteilen, wie er glaubt, daß Sie, mein Führer, den Fall selbst beurteilen würden. Heil mein Führer! In Treue, Ihr politischer Soldat Roland Freisler.] 
Somente mais de três décadas após o final da Segunda Guerra Mundial, tornaram-se temas no Parlamento Alemão, na Academia (como Hillermeier, 1980) e no cinema (Verhoeven, 1982) a atuação do nazismo contra opositores políticos (sumariamente condenados) e também a legitimidade $^{13}$ ou não de sua legislação e seu Judiciário. Entretanto, alguns parlamentares julgavam desnecessária a promulgação de uma lei federal que anulasse as sentenças nazistas (devido à existência de algumas leis menos abrangentes), enquanto outros acreditavam ser dever do Parlamento não permitir que ainda houvesse pessoas marcadas por condenações arbitrárias e injustas.

Perspectiva ilustrada na sessão parlamentar de 04/03/1998, na qual o representante da coligação CDU/CSU, Nobert Geis, expõe-se da seguinte maneira em sua primeira fala (tradução nossa): "Por que isso agora, depois de 50 anos? Havia leis de estados federados, pelo menos nos estados ocidentais, com base nas quais já se procedeu às reabilitações. Poderia surgir a impressão de que nada aconteceu nos últimos 50 anos" $^{14}$. Mais adiante no debate, Geis pergunta à representante do SPD, Dr. Herta Däubler-Gmelin (tradução nossa): "Não estaremos indo longe demais, senhora deputada?"15.

\section{Unrecht, a Injustiça no nazismo}

Em uma leitura preliminar dos depoimentos de Hirzel e Müller no Parlamento Alemão, destacou-se a recorrência do conceito alemão Unrecht em diversas passagens, como podemos aferir nas expressões elencadas abaixo:

\footnotetext{
${ }^{13}$ Segundo Ferraz Jr. (2009, p. 58), a legitimidade no direto "trata-se do reconhecimento, em última instância, das decisões do detentor do poder".

${ }^{14}$ Warum das jetzt nach 50 Jahren? Es gab doch Länderregelungen, zumindest in den westlichen Bundesländern, nach denen rehabilitiert worden ist. Es könnte der Eindruck entstehen, in den vergangenen 50 Jahren sei nichts geschehen.

${ }^{15}$ Gehen wir da nicht zu weit, Frau Kollegin?
} 


\begin{tabular}{|c|c|c|}
\hline Direito considerado verdadeiro & vs. & $\begin{array}{l}\text { Injustiça praticada pelo nazis- } \\
\text { mo }\end{array}$ \\
\hline $\begin{array}{l}\text { direito verdadeiro } \\
\text { (wirkliches Recht) }\end{array}$ & \multirow{7}{*}{$X$} & $\begin{array}{c}\text { tribunal de fachada } \\
(\text { Scheingericht })\end{array}$ \\
\hline $\begin{array}{c}\text { licitude real } \\
\text { (tatsächliche Rechtmäßigkeit) }\end{array}$ & & $\begin{array}{l}\text { Injustiça juridicamente formaliza- } \\
\qquad \mathrm{da} \\
\text { (rechtsförmiges Unrecht) }\end{array}$ \\
\hline $\begin{array}{l}\text { tribunal verdadeiro } \\
\text { (wirkliches Gericht) }\end{array}$ & & $\begin{array}{c}\text { regime de Injustiça } \\
\text { (Unrechtsregime) }\end{array}$ \\
\hline $\begin{array}{l}\text { juiz verdadeiro } \\
\text { (wirklicher Richter) }\end{array}$ & & $\begin{array}{l}\text { Judiciário político nazista } \\
\text { (politische NS-Justiz) }\end{array}$ \\
\hline $\begin{array}{l}\text { lícito / legal (de lei) } \\
\text { (rechtmäßig) }\end{array}$ & & $\begin{array}{l}\text { Injustiça institucionalizada } \\
\text { (institutionalisiertes Unrecht) }\end{array}$ \\
\hline $\begin{array}{c}\text { independência de poder estatal } \\
\text { (Unabhängigkeit von der Staats- } \\
\text { macht) }\end{array}$ & & $\begin{array}{l}\text { desejo de praticar a Injustiça } \\
\text { (Unrecht-Wollen) }\end{array}$ \\
\hline $\begin{array}{l}\text { o direito pensado em termos de } \\
\text { decência } \\
\text { (das sittlich gedachte Recht) }\end{array}$ & & $\begin{array}{l}\text { conceito de Injustiça } \\
\text { (Unrechtskonzept) }\end{array}$ \\
\hline
\end{tabular}

Frente a esse quadro, que ilustra a complexidade semântica do vocábulo Unrecht, destacaremos alguns pontos das obras de Silva (2011) e Stolleis (1994) quanto ao estado de injustiça extrema, concentrado no conceito de Unrecht, e à validade do direito e das práticas jurídicas de sistemas totalitários, como o nazismo.

Stolleis (1994) ressalta a paradoxalidade da fórmula que dá nome à sua obra Recht im Unrecht (Justiça na Injustiça, tradução livre), pois “[...] insere-se nela o dilema da 'justiça' ${ }^{16}$ em um sistema 'ilegal' em sua totalidade ou, pelo menos, um sistema que produz injustiça em muitos dos casos" ${ }^{17}$ (Stolleis, 1994, p. 7, tradução nossa). Para entendê-la, o autor propõe três reflexões. Segundo a primeira, nenhuma tirania exerceria seu governo na

\footnotetext{
16 Segundo definição do Dicionário Jurídico e Económico (Jayme et al., 2013, p. 389), o verbete "Recht" pode referir-se aos seguintes termos em português: justiça; legislação; direito, regra jurídica, norma, lei; poder, entre outros. Sendo assim, as traduções desse termo para o português podem variar em consonância com seus respectivos contextos.

17 [...] steckt in ihr das Dilemma des "Rechts" in einem insgesamt "unrechtmäßigen" oder jedenfalls in vielen Fällen Unrecht produzierenden System.
} 
sua totalidade posto que, mesmo nas mais extremas, há resquícios de justiça e áreas jurídicas nas quais ainda se procede licitamente. Além disso, "sempre há pessoas que não se deixam transformar totalmente em criminosos, que resistem à pressão política e se comportam 'em conformidade com as normas' não somente em relações pessoais, mas, sobretudo, também nas suas funções oficiais" ${ }^{18}$. Aqui, segundo o autor, a noção de direito está muito próxima ou se funde à de moral.

A segunda argumentação de Stolleis (1994, p. 7-8) consiste na formalidade legal e renuncia à diferenciação entre "direito" e "não-direito", o qual abrange infrações legais e todas as normas sem qualidade jurídica (como os costumes). Considera "direito" tudo aquilo que satisfaça requisitos formais, assim, associa a noção de "direito" à constituição:

\footnotetext{
É da própria constituição que emanam os requisitos. Se a constituição reduz-se à frase de que a vontade do Führer é lei e decide sobre o que é justiça e o que é injustiça, então toda a declaração de vontade estatal manifestada com pretensão de validade legal é justa na medida em que ela corresponder a essa vontade. ${ }^{19}$ (Stolleis, 1994, p. 8, tradução nossa)
}

Já sua última reflexão refere-se à negação completa da qualidade jurídica de todos os atos jurídicos entre 1933 e 1945 (Stolleis, 1994, p. 8). Dessa forma, o nazismo seria considerado incapaz de elaborar leis desde seu início, o que também anularia todas as leis precedentes. Todas essas perspectivas apresentadas pelo autor, ainda no início de sua obra, já remetem à complexidade da definição do conceito de Unrecht.

Antes de tratar desse conceito, Silva (2011) destaca o Tribunal de Nuremberg (1945-1949) e o julgamento dos soldados de fronteira da exAlemanha Oriental depois da reunificação alemã (1991-2004) como tentativas de punição de perpetradores após regimes totalitários. No primeiro

\footnotetext{
18 Stets gibt es Menschen, die sich nicht vollständig zu Tätern machen lassen, die dem politischen Druck widerstehen und sich 'regelmäßig' verhalten, nicht nur in privaten Beziehungen, sondern vor allem auch als Amtsträger. (loc. cit., tradução nossa)

19 Welche Anforderungen dies sind, ergibt sich aus der Verfassung. Ist die Verfassung auf den Satz reduziert, daß der Wille des Führers Gesetz ist und über Recht und Unrecht entscheidet, dann ist jede mit Geltungsanspruch auftretende staatliche Willensäußerung Recht, soweit sie diesem Willen entspricht.
} 
caso, o autor ressalta que a questão mais importante não eram as leis vigentes durante a perpetração dos crimes, mas "uma noção de justiça mais ampla, que ultrapassaria as fronteiras entre os países e estaria acima de qualquer lei estatal" (Silva, 2011, p. 89), correspondente à primeira reflexão de Stolleis (1994).

Já no segundo caso, a principal discussão girava em torno do princípio fundamental do Direito Penal nullum crimen sine lege ("não há crime sem lei anterior que o defina"), ou seja, "não importa a gravidade da conduta, se ela não era considerada crime na época de sua realização, o agente não poderá ser punido criminalmente" (Silva, 2011, p. 89). Concepção condizente com a célebre afirmação de Hans Filbinger ${ }^{20}$ : "o que era justiça naquela época, não pode ser Injustiça hoje"21 (cf. Stolleis, 1994, p. 238). Caso essa premissa, correspondente à segunda argumentação de Stolleis (1994), fosse levada a cabo, as sentenças proferidas pelos tribunais nazistas não poderiam ser anuladas, visto que suas ações estavam ancoradas na legislação da época.

Entretanto, em 1946 foi publicado um artigo do jusfilósofo Gustav Radbruch considerado uma importante contribuição teórica ao debate em torno da classificação como crime de atos cometidos por regimes totalitários, argumentando que o "Direito injusto não pode ser considerado Direito" (Correia Jr, 2011, s.p.). Posteriormente, essas premissas passaram a ser conhecidas na literatura como fórmula de Radbruch (cf. Silva, 2011).

Com base nessa breve introdução teórica acerca do termo central desse artigo, Unrecht, identificamos nos fragmentos a seguir um claro jogo de antíteses entre dois pólos. Frequentemente, o conceito de Unrecht é posto em oposição a uma noção de "direito considerado verdadeiro", a "Justiça". Portanto, neste artigo, optamos por traduzi-lo como "Injustiça". No primeiro exemplo, Hirzel refere-se a duas conjunturas opostas:

(I). Mas essa ideia [o Tribunal do Povo como tribunal legítimo] [...] ignora o conhecimento fundamental que devemos aos estados totalitários, a saber: que existe a Injustiça juridicamente formali-

\footnotetext{
${ }^{20}$ Hans Filbinger atuou como juiz da marinha nazista e primeiro-ministro em Baden-Württemberg entre 1966 e 1978.

${ }^{21}$ Was damals Recht war, kann heute nicht Unrecht sein.
} 
zada e também a Injustiça posta em prática pela lei ou institucionalizada, que, portanto, ignora que podem existir leis formalmente corretas que, apesar disso, são nulas por causa de seu conteúdo material juntamente com tudo o que se baseia nelas. Consequentemente, também ignora que, quando há a suspeita justificada de que uma instituição posta em atividade pela lei é um instrumento de um mero desejo de praticar a Injustiça, para eliminar a suspeita não basta alegar que a instituição, afinal, estaria em funcionamento com base numa lei correta e formalmente promulgada, mas deve ser verificado se a alegada legitimidade da lei e da instituição fundamentada nela são mais do que uma mera ficção; se a lei e a instituição realmente podem reivindicar para si o direito verdadeiro. ${ }^{22}$ (Hirzel, p. 17/9, grifos nossos) ${ }^{23}$

Com exceção da última expressão destacada, todas as outras se relacionam diretamente ao estado de Injustiça nazista, questionando-a enquanto um tipo de "justiça" formalmente legalizada, portanto, válida. Além da menção direta ao conceito Unrecht, os adjetivos nulas, mero (bloß), alegada (vorgeblich) e mera evidenciam mais marcadamente a oposição a uma outra "justiça", associada à noção de direito verdadeiro (wirkliches Recht), expressão que encerra o parágrafo.

Nos próximos exemplos, Hirzel (II) e Müller (III) também evocam essa antítese ao tratarem da discussão acerca da natureza jurídica do "Tribunal do Povo" e de suas sentenças:

(II). Com relação ao Tribunal do Povo - de agora em diante irei designá-lo assim, de forma breve, sem mencionar sempre suas indispensáveis aspas - há hoje, em termos muito gerais, duas concepções no nosso mundo. Segundo a primeira, o Tribunal do Povo era um tribunal regular no sentido da Lei Alemã da Organi-

\footnotetext{
22 Diese Anschauung [...] ignoriert aber die grundlegende Erkenntnis, die wir den totalitären Staaten verdanken, daß es nämlich das rechtsförmige Unrecht, auch das per Gesetz praktizierte oder institutionalisierte Unrecht gibt, daß es also formal ordnungsgemäße Gesetze geben kann, die dennoch wegen ihres materiellen Inhalts nichtig sind samt allem, was sich darauf stützt, daß demnach, wenn der begründete Verdacht besteht, daß eine per Gesetz tätige Institution Werkzeug eines bloßen UnrechtWollens ist, es zur Ausräumung des Verdachts nicht genügt, darauf zu verweisen, daß die Institution ja tätig sei auf Grund eines ordnungsgemäß erlassenen Gesetzes, sondern daß geprüft werden muß, ob vorgebliche Rechtmäßigkeit von Gesetz und darauf gründender Institution mehr sind als eine bloße Fiktion, ob Gesetz und Institution wirkliches Recht für sich in Anspruch nehmen können.

${ }^{23}$ Todas as traduções apresentadas nesse artigo foram elaboradas pela autora desse artigo.
} 
zação Judiciária; segundo a outra, uma mera máquina assassina, como diz a expressão cristalizada, e, portanto, não era um tribunal, mas um mero tribunal de fachada. Segundo a primeira, o Tribunal do Povo estava autorizado a proferir sentenças válidas. [...] A opinião contrária diz: tal procedimento pressupõe que o Tribunal do Povo teria sido um tribunal verdadeiro, e é exatamente isso o que nós contestamos; o que o chamado Tribunal do Povo produziu como chamadas sentenças representaram sentenças inexistentes no sentido jurídico, sendo que o conteúdo material dessas não-sentenças é totalmente irrelevante. ${ }^{24}$ (Hirzel, p. 17/7, grifos nossos)

(III). Até hoje, a natureza jurídica do Tribunal do Povo não foi explicitamente tematizada. Na resposta do secretário estadual parlamentar Dr. Klein ao seu pedido, Sr. Kleinert, pode-se verificar, por exemplo, quais opiniões o Tribunal Superior de Justiça [BGH] alemão manifestou sobre isso. Lá podemos ler:

Nas decisões que tinham como assunto uma avaliação das sentenças do Tribunal do Povo, o Tribunal Superior de Justiça partiu tacitamente - tacitamente! - do princípio de que o Tribunal do Povo era formalmente - isto é, no sentido das leis vigentes naquele tempo - um "tribunal". ${ }^{25}$ (Müller, p. 17/19, grifos nossos)

No fragmento II, Hirzel aponta para a indispensabilidade das aspas ao se tratar do "Tribunal do Povo" posto que, assim como Müller, não o considera como um tribunal verdadeiro (wirkliches Gericht): "é exatamente

\footnotetext{
${ }^{24}$ Bezüglich des Volksgerichtshofs - ich werde ihn von jetzt an kurz so nennen, ohne die erforderlichen Anführungszeichen immer mitzuerwähnen - sind in ganz großen Zügen heute zwei Auffassungen bei uns in der Welt. Nach der ersten war der Volksgerichtshof ein ordentliches Gericht im Sinne des Gerichtsverfassungsgesetzes, nach der anderen eine bloße, wie der eingebürgerte Ausdruck lautet, Mordmaschine und damit kein Gericht, sondern ein bloßes Scheingericht. Nach der ersten konnte der Volksgerichtshof gültige Urteile sprechen. [...] Die Gegenmeinung sagt: Ein solches Vorgehen setzt voraus, daß der Volksgerichtshof ein wirkliches Gericht war, und eben dies bestreiten wir; was der sogenannte Volksgerichtshof als sogenannte Urteile produzierte, stellte im Rechtssinne gar keine Urteile dar, wobei es auf den materiellen Inhalt dieser Nichturteile überhaupt nicht ankommt.

${ }^{25}$ Bis heute ist die Rechtsnatur des Volksgerichtshofs nicht ausdrücklich thematisch behandelt worden. Welche Sätze der Bundesgerichtshof dazu von sich gegeben hat, kann man z. B. in der Antwort des Parlamentarischen Staatssekretärs Dr. Klein auf eine Anfrage von Ihnen, Herr Kleinert, nachlesen. Dort heißt es:

Der Bundesgerichtshof ist in den Entscheidungen, die eine Wertung von Urteilen des Volksgerichtshofs zum Gegenstand hatten, stillschweigend

- stillschweigend! -

davon ausgegangen, daß der Volksgerichtshof formal, das heißt, im Sinn der zur Zeit der NS-Herrschaft geltenden Vorschriften, ein "Gericht" war.
} 
isso o que nós contestamos". Hirzel expõe duas visões opostas correntes à época: tribunal regular (ordentliches Gericht) x mera máquina assassina (eine bloße [...] Mordmaschine); tribunal verdadeiro (wirkliches Gericht) x mero tribunal de fachada (ein bloßes Scheingericht). Consequentemente, seus produtos também passam nas oposições pelo crivo da legalidade: sentenças válidas (gültige Urteile) x chamadas sentenças (sogenannte Urteile) e sentenças inexistentes no sentido jurídico (im Rechtssinne gar keine Urteile) x não-sentenças (Nichturteile).

Tais considerações, legitimando os tribunais nazistas e suas ações, remetem à segunda reflexão de Stolleis (1994), ao restringir o direito às leis nazistas então vigentes. Entretanto, tal abordagem desconsidera outras questões também presentes como a submissão do sistema jurídico à ideologia nazista e o autoritarismo e a parcialidade dos operadores do direito. $\mathrm{Na}$ segunda audiência contra a Rosa Branca, da qual Hirzel e Müller foram réus, o juiz vociferou: “Já se foram os tempos em que cada um podia andar por aí com sua própria 'crença' política! Para nós, há somente uma medida, a nacional-socialista. Ela é a medida de todas as coisas!" (Scholl, 2014, p. 132). Müller acrescenta detalhes da postura desse juiz:

(IV). Freisler abriu a audiência com a frase: se aqui alguém disser alguma coisa que não me agrada, então mandarei que o levem preso. - Seis semanas antes, Sophie Scholl e Hans Scholl [...] haviam lhe respondido à altura, tornando a situação por vezes vexatória para Freisler naquela audiência de 22 de fevereiro de 1943. - E isso foi só a abertura da nossa audiência. ${ }^{26}$ (Müller, p. 17/20)

Karin Schüddekopf, uma jovem que integrou os 14 réus do segundo processo contra a Rosa Branca, relembra que não havia advogados de defesa na sala de audiência, mas membros do partido nazista e policiais, sendo que os únicos civis eram da Gestapo. Os advogados atribuídos aos réus não os defendiam das acusações (Vielhaber, 1963, p. 101-105). Além disso, o próprio Freisler respondia às perguntas que fazia aos réus, sendo que "seu forte era calar os adversários no grito, não em convencer com argumen-

\footnotetext{
${ }^{26}$ Freisler eröffnete die Verhandlung mit dem Satz: Wenn hier einer etwas sagt, was mir nicht paßt, dann lasse ich ihn abführen. - Sechs Wochen vorher hatten ihm Sophie Scholl und Hans Scholl [...] entsprechend Paroli geboten, und er sah in dieser Verhandlung am 22. Februar 1943 teilweise schlecht aus. - Das war die Grundeinstimmung auf die Verhandlung.
} 
tos" 27 (Vielhaber, 1963, p. 104, tradução nossa), semelhante à postura de Hitler, o qual "gritava em convulsões" em seus discursos (Klemperer, 2009, p. 106). Freisler ilustra ao extremo a submissão dos correligionários nazistas, posto que "naquela época [...] as pessoas eram educadas, precisamente por Hitler, a ver a máxima virtude na obediência cega de suas ordens..." (Canetti, 2011, p. 187) ${ }^{28}$.

Tal contexto da audiência contra Hirzel e Müller constitui um cenário representativo, em menor escala, do modus operandi nazista frente a seus opositores, bem como faz parte do seu discurso, pois “a encenação, por sua vez, também influencia o tom das palavras e lhes proporciona um colorido mais vivo" (Klemperer, 2009, p. 104). Por outro lado, esse "cenário" também corrobora a necessidade de anulação das sentenças nazistas, posto a total parcialidade que as fundamentava, como acentua Hirzel:

(V). Não se pode considerar um tribunal como um tribunal autêntico quando este detém como princípio decisivo do direito penal o princípio de que tudo se mede pelo conceito de uma pessoa cujo conceito abrange precisamente, em sua parte essencial, os piores crimes coletivos. No confrontamento entre o Professor Huber, de um lado, e Freisler, de outro, foi, no fundo, o réu quem representou o bem jurídico ${ }^{29}$ e quem pretendia proteger o artigo $80^{30}$, parágrafo $2^{\circ}$ do Código Penal Alemão (StGB) contra um represen-

\footnotetext{
27 Seine Stärke lag im Überschreien, nicht im Überzeugen.

28 Segundo Arendt (1989, p. 373), os movimentos totalitários caracterizam-se "pela exigência de lealdade total, irrestrita, incondicional e inalterável de cada membro individual. Essa exigência é feita pelos líderes dos movimentos totalitários mesmo antes de tomarem o poder e decorre da alegação, já contida em sua ideologia, de que a organização abrangerá, no devido tempo, toda a raça humana. [...] lealdade total que é a base psicológica do domínio total. Não se pode esperar essa lealdade a não ser de seres humanos completamente isolados que, desprovidos de outros laços sociais - de família, amizade, camaradagem - só adquirem o sentido de terem lugar neste mundo quando participam de um movimento, pertencem ao partido".

29 Segundo Teles (2004, p. 13), o "bem jurídico" podem referir-se a "coisas importantes, materiais ou espirituais" que "exatamente porque são importantes e têm valor, podem ser atacadas e, por isso, devem ser protegidas" pelo Direito Penal, são eles: “a vida, a liberdade, a propriedade, o casamento, a família, a honra, a saúde, enfim, todos os valores importantes para a sociedade". Em consonância com Teles, Silva (2014, p. 319) define bem jurídico como "coisa, material (valor econômico) ou imaterial (interesse moral), que constitua ou possa constituir objeto de direito".

${ }^{30}$ No estado atual dessa pesquisa, ainda não ficou claro de qual Código Penal Alemão (Strafgesetzbuch) essa passagem trata.
} 
tante do poderio estatal, o mesmo que aboliu justamente esse bem jurídico. ${ }^{31}$ (Hirzel, p. 17/16, grifos nossos)

Novamente são colocadas em evidência oposições como um tribunal (ein Gericht) x tribunal autêntico (echtes Gericht), poderio estatal (Staatsmacht) x bem jurídico (Rechtsgut) e, a mais simbólica, Freisler x Professor Huber. Nessa contraposição, os elementos enumerados por Hirzel também se referem aos conceitos de Unrecht e do direito considerado verdadeiro.

(VI). Um sistema de Injustiça, que é tão gritantemente um sistema de Injustiça como esse, tem primeiramente a obrigação de abolir-se a si mesmo ou de transformar-se em um sistema de direito. ${ }^{32}$ (Hans Hirzel, p. 17/17, grifos nossos)

Hirzel determina, assim, as duas únicas possibilidades para a validação de um sistema totalitário: sua anulação ou transformação em um sistema de direito (Rechtssystem). Apesar da anulação de leis promulgadas pelo nazismo, o julgamento de alguns de seus criminosos nos Julgamentos de Nuremberg e a política de Desnazificação, ainda havia na década de 1980 a incerteza quanto à vigência de sentenças penais de tribunais nazistas e políticos divididos quanto à sua validade jurídica. Essa contradição no tratamento oficial dado a esses tribunais é evidenciada no fragmento (VII), no qual Hirzel aponta à necessidade de coerência na apreciação de sistemas injustos ao recorrer à repetição do termo esquizofrênico (schizophren):

(VII). Além disso, esse princípio também se aplica necessariamente àqueles "tribunais" ou àquelas instituições que tinham a função tão predominante de defender justamente o sistema de Injustiça enquanto sistema de Injustiça e, por isso, eu acho que reconhecer essas instituições como verdadeiras apesar de tudo, significa

\footnotetext{
${ }^{31}$ Man kann ein Gericht nicht als echtes Gericht betrachten, wenn es als den entscheidenden Strafgesetzgrundsatz den Grundsatz hat, alles mißt sich an dem Konzept eines Menschen, dessen Konzept eben im wesentlichen Teil größte Kollektivverbrechen umfaßt. In der Konfrontation zwischen Professor Huber auf der einen Seite und Freisler auf der anderen Seite war es im Grunde der Angeklagte, der das Rechtsgut, das der $\S 80$ Abs. 2 StGB schützen wollte, vertrat gegen einen Vertreter der Staatsmacht, der eben dieses Rechtsgut abschaffte.

32 Ein Unrechtssystem, das so kraß ein Unrechtssystem ist wie dieses, hat zuerst die Pflicht, sich selbst abzuschaffen oder zu wandeln zu einem Rechtssystem hin.
} 
uma contradição em si. Se quiséssemos fazer isso, teríamos que ser esquizofrênicos. Isso não é possível. E, se o fizéssemos no caso do Terceiro Reich, deveríamos ou pensar da mesma forma sobre sistemas de Injustiça atuais ou futuros em qualquer outro lugar no mundo - então não haveria mais nenhuma possibilidade de contradição -, ou teríamos que ser, novamente, esquizofrênicos ao julgarmos de forma diferente sistemas de outros lugares do que havíamos julgado nosso próprio passado. ${ }^{33}$ (Hirzel, p. 17/17-18, grifos nossos)

Os argumentos apresentados nos fragmentos acima em favor da necessidade de anulação retroativa das sentenças penais nazistas, remetemnos ao surgimento e aplicação da fórmula de Radbruch, possível, sobretudo, em situações limítrofes nas quais a identificação do "direito estritamente à lei" escrita (Silva, 2011, p. 89) parece afastar o direito de uma noção de justiça e se aproximaria mais claramente de uma "injustiça insuportável" (SILVA, 2011, p. 97, grifo do autor) que não deve prevalecer sobre a justiça, assim como pontua Radbruch (apud Silva, 2011, p. 95):

O conflito entre a justiça e a segurança jurídica deve ser resolvido de forma que o direito positivo [...] tenha preferência mesmo que seu conteúdo seja injusto e inadequado, a não ser que a contradição entre a lei posta e a justiça atinja um nível insuportável, caso em que a lei, por ser "direito injusto", deve ceder em favor da justiça. ${ }^{34}$

Assim como esclarece Silva (2011, p. 87-88), ao se tratar da aplicação da fórmula de Radbruch em casos de injustiça em "nível insuportável", como em períodos de justiças transicionais, entra-se no debate teórico em

\footnotetext{
${ }^{33}$ Dieser Grundgedanke überträgt sich dann zwangsläufig auch auf diejenigen "Gerichte" oder Einrichtungen, die ganz überwiegend die Funktion hatten, eben das Unrechtssystem als Unrechtssystem zu schützen, und darum meine ich, es bedeutet einen Denkwiderspruch, diese Institutionen trotz allem als wirkliche Gerichte anzuerkennen. Wir müßten uns, wenn wir das tun wollten, schizophren verhalten. Das ist nicht möglich. Und wir müßten, wenn wir es im Falle des Dritten Reichs machten, bei einem heutigen oder künftigen Unrechtssystem irgendwo anders auf der Welt entweder ebenso denken - dann haben wir keine Möglichkeit des Widerspruchs mehr - oder wieder schizophren sein, indem wir dort anders urteilen, als wir unsere eigene Vergangenheit beurteilt haben.

34 Trecho em alemão incluído pela autora do artigo (Radbruch, 1999, p. 216): Der Konflikt zwischen der Gerechtigkeit und der Rechtssicherheit dürfte dahin zu lösen sein, daß das positive [...] Recht auch dann den Vorrang hat, wenn es inhaltlich ungerecht und unzweckmäßig ist, es sei denn, daß der Widerspruch des positiven Gesetzes zur Gerechtigkeit ein so unerträgliches Maß erreicht, daß das Gesetz als "unrichtiges Recht" der Gerechtigkeit zu weichen hat.
} 
torno do conceito de segurança jurídica e de "dicotomias clássicas da filosofia do direito e da teoria da justiça, que não estão aí para serem 'resolvidas'”, baseadas nas relações entre direito $x$ justiça; direito $x$ lei; justiça $x$ punição; memória $x$ verdade; verdade $x$ punição.

\section{Considerações finais}

Nesse artigo apresentamos um breve panorama do percurso históricojurídico desde a reformulação legislativa e governamental, a partir da ascensão de Hitler ao poder em 1933, até o período do Pós-guerra. Neste, iniciaram-se diversos debates no Parlamento Alemão que culminaram na promulgação, em 1998, de uma lei federal de anulação retroativa das sentenças penais proferidas por tribunais nazistas.

Em consonância com a temática da atual edição da Tradução em Revista, dedicada à tradução especializada, traçamos um plano de fundo para o estudo realizado na segunda parte do artigo, dedicado ao conceito de Unrecht, a fim de preparar a tradução de fragmentos selecionados dos depoimentos de dois ex-integrantes do grupo de resistência Rosa Branca, Hans Hirzel e Franz Müller, inaugurando a série de debates parlamentares entre 1984 e 1998.

O estudo apresentado nesse artigo integra uma série de pesquisas acadêmicas e publicações iniciadas em 2010 com o projeto "A Rosa Branca: tradução de textos selecionados" ${ }^{35}$. Após lançamento do livro A Rosa Branca (Scholl, 2013) junto a painéis da exposição permanente da Fundação Rosa Branca [Weiße Rose Stiftung, em Munique], a história do grupo passou a ser mais divulgada no Brasil ${ }^{36}$, contando com traduções diretas do alemão ${ }^{37}$ já publicadas e outras atualmente em desenvolvimento como dissertações de mestrado ${ }^{38}$.

\footnotetext{
35 Projeto desenvolvido entre 2010 e 2013, fomentado pelo Programa Ensinar com Pesquisa e coordenado pelas Prof. ${ }^{\text {as }}$ Dr. ${ }^{\text {as }}$ Juliana Perez e Tinka Reichmann.

36 Reichmann, Schäfer \& Salgado, 2016; Reichmann \& Schäfer, 2016; Utida, 2015; Reichmann \& Perez, 2012.

37 Scholl, 2013; Schäfer, 2015.

38 Trata-se das dissertações de mestrado Tradução e memória: a legendagem de um filme-testemunho sobre a Rosa Branca, de Yasmin Utida, e A Rosa Branca e a Correção da (In)Justiça Nacional-socialista no Pós-Guerra: Interface entre História, Direito e Tradução, em desenvolvimento pela autora deste artigo.
} 


\section{Referências}

ALEMANHA. Lei Gesetz zur Aufhebung nationalsozialistischer Unrechtsurteile in der Strafrechtspflege (NS-AufhG), de 25 de agosto de 1998. Lei de revogação das sentenças penais da Injustiça extrema nazista na aplicação da justiça penal (LA-N) de 25 de agosto de 1998 (BGBl. I S. 2501) que foi modificada pela última vez por meio do artigo $1^{\circ}$ da lei de 24 de setembro de 2009 (BGBl. I S. 3150). Disponível em: <http://www.gesetze-iminternet.de/ns-aufhg/BJNR250110998.html>. Acesso em: 12 ago. 2016.

ARQuivo Do PARlamento Alemão. Oficio no 1402 E - 706/82, de 20 de janeiro de 1983. A Franz Müller. Anexo 1 do Protocolo de Resolução no 17 sobre a 17ª sessão da Delegação de Direito, de 14 de março de 1984: Ofício enviado pela Secretaria de Justiça do Estado Federado de BadenWürttemberg em resposta a uma solicitação de Franz Müller. Serviço de Documentação Parlamentar (Parlamentsdokumentation), Impresso 10/116, BT 03623.84

Protocolo Estenográfico no 17 sobre a $17^{\text {a }}$

sessão da Delegação de Direito, de 14 de março de 1984. Requerimento de representantes do Partido Socialdemocrata da Alemanha (SPD): Anulação das decisões dos instrumentos do regime de Injustiça extrema nazista designados como "Tribunal do Povo" e "Tribunais Especiais Políticos" - Oitiva não oficial de dois depoentes. Berlim. Serviço de Documentação Parlamentar (Parlamentsdokumentation), Impresso 10/116, BT 03623.84.

ARENDT, H. Totalitarismo. In: Origens do Totalitarismo. Trad. Roberto Raposo. São Paulo: Companhia das Letras, 1989, p. 339-531.

CANETTI, E. Hitler, por Speer. In: 1905-1994. A Consciência das Palavras: Ensaios. Trad. Márcio Suzuki; Herbert Caro ("O outro processo"). São Paulo: Companhia das Letras, 2011, p. 175-202.

CARNEIRO, M. L. T. Metáforas Roubadas à Doença: Particularidades do Discurso Racista. In: CARneiro, M. L. T.; MONTEIRO, Y. N. (Orgs.). As Doenças e os Medos Sociais. São Paulo: Editora Fap-Unifesp, 2012, p. 251-267.

CORREIA JR., R. A fórmula de Radbruch e as decisões brasileiras. In: Âmbito Jurídico, Rio Grande, XIV, n. 87, abr 2011. Disponível em: $<$ http://www.ambito-

juridico.com.br/site/index.php?n_link=revista_artigos_leitura\&artigo_id=92 97>. Acesso em: 15 de out. 2016.

DOKUMENTARCHIV.DE. Gesetz zur Änderung des Strafrechts und des Strafverfahrens vom 24. April 1934. Disponível em: <http://www.documentarchiv.de/ns/1933/stgb-landes-hochverratvolksgerichtshof_ges.html>. Acesso em: 12 ago. 2016.

DUDEN. Deutsches Universalwörterbuch, 67 ed. Mannheim, Leipzig, Wien, Zürich: Dudenverlag, Bibliographisches Institut \& F.A. Brockhaus, 2006. 
FERRAZ JR., T. S. Estudo de Filosofia do Direito. Reflexões sobre o poder, a liberdade, a justiça e o direito. $3^{\mathrm{a}}$ ed. São Paulo: Atlas, 2009.

HAFT, F. Der Volksgerichtshof: Kein Gericht, sondern Terrorinstrument. In: Aus der Waagschale der Justitia. München: Beck, 2009, p. 247-251.

Hillermeier, H. (Org.). "Im Namen des deutschen Volkes!": Todesurteile des Volksgerichtshofs. Darmstadt; Neuwied: Luchterhand, 1980.

Hudemann, R. Posfácio à edição brasileira. In: ScHOll, I. A Rosa Branca. A história dos estudantes alemães que desafiaram o nazismo. 2 ${ }^{a}$ ed. PEREZ, J.; ReichmanN, T. (Orgs.); SCHÄFER, A.; Alves, E.; SANTOS, E.; BONATTO, F.; SALGADO, J.; BENASSI, R.; UTIDA, Y. São Paulo: Editora 34, 2014, p. 239-258.

JAYME, E.; NeUSS, J.-J.; VeIGA, M. de F.; RICHTER, T. Wörterbuch der Rechtsund Wirtschaftssprache. Dicionário Jurídico e Económico. Deutsch-Portugiesisch / Alemão-Português. Vol. 2. Munique: C. H. Beck, 2013.

KLEMPERER, V. LTI: a linguagem do Terceiro Reich. Trad. Miriam Bettina Paulina Oelsner. Rio de Janeiro: Contraponto, 2009.

RADBRUCH, G. Gesetzliches Unrecht und übergesetzliches Recht (1946). In: Rechtsphilosophie (Studienausgabe). Heidelberg: C. F. Müller, 1999, p. 211-219. RÄTSCH, B. Volksgerichtshof. Bühne für Prozesse einer willfährigen Justiz. In: GITTERN, Hinter. Schriftsteller und Journalisten vor Volksgerichtshof 19341945. Bonn; Berlin: Bouvier, 1992, p. 7-20.

REICHMANN, T.; SCHÄFER, A. C.; SALGADO, J. L. A Rosa Branca: contribuições da tradução para a difusão de fontes sobre a resistência antinazista. In: Revista Graphos, Universidade Federal da Paraíba, vol. 18, no 2. Paraíba: PPGL/UFP, 2016. No prelo.

ReICHMANN, T.; PEREZ, J. P. Seis panfletos: história, retórica e tradução. In: AtAYAN, V.; WIENEN, U. (eds.). Sprache - Rhetorik - Translation. Frankfurt/M.: Lang, 2012, pp. 213-223.

SCHÄFER, A. C. ; REICHMANN, T. Die Übertragung von Inge Scholls Die Weiße Rose ins brasilianische Portugiesisch: zum didaktischen Potenzial eines Übersetzungsprojekts. In: ANDRES, D.; RICHTER, J.; SCHIPPEL, L. (Org.). Translation und 'Drittes Reich': Menschen - Entscheidungen - Folgen. Berlim: Frank \& Timme, 2016, Vol. 1, pp. 323-336.

SCHÄFER, A. C. Quando a tradução (re)conta a História: análise textual e tradução comentada de interrogatórios da "Rosa Branca". 406 f. Dissertação (Mestrado) - Faculdade de Filosofia, Letras e Ciências Humanas, Universidade de São Paulo, São Paulo, 2015.

SCHOll, I. A Rosa Branca. A história dos estudantes alemães que desafiaram o nazismo. Perez, J. \& ReICHMANN, T. (Org.); SCHÄFER, A.; Alves, E.; SANTOS, E.; BonAtTO, F.; SAlgAdO, J.; BENASSI, R.; UtidA, Y. São Paulo: Editora 34, 2014 (1ํㅡㄹ ed. 2013).

SCHOLL, I. Die Weiße Rose. Frankfurt: S. Fischer, 1994. 
SILVA, P. Vocabulário Jurídico. 31aㅡ ed. rev. FILHO, N. S.; GOMES, P. P. V. (Revs.). Rio de Janeiro: Forense, 2014.

SILVA, M. V. P. da. Controle e normalização: Michel Foucault e a relação entre corpo e poder. In: Domus on line: rev. Teor. pol. soc. Cidad., Salvador, v. 3, jan./dez. 2008, p. 87-98.

SILVA, V. A. da. Transição e direito: culpa, punição, memória. In: GALLE, H.; SCHMIDT, R. (Orgs.). A memória e as ciências humanas. São Paulo: Humanitas, 2011, p. 87-106. Disponível em: $<$ http://www.teoriaedireitopublico.com.br/pdf/2011Transicao_e_direito.pdf $>$. Acesso em: 12 ago. 2016.

STOLLEIS, M. Recht im Unrecht. Studien zur Rechtsge schichte des Nationalsozialismus. Frankfurt am Main: Suhrkamp, 1994.

TELES, N. M. Direito penal: parte geral. V. 4. São Paulo: Atual, 2004.

UTIDA, Y. C. Tradução e memória: a legendagem de um filme-testemunho sobre a Rosa Branca. Dissertação (Mestrado) - Faculdade de Filosofia, Letras e Ciências Humanas, Universidade de São Paulo, São Paulo. No prelo. UTIDA, Y. C. O corpo como escrita da memória: o testemunho no documentário "Os resistentes: testemunhas da Rosa Branca", de Katrin Seybold. In: Revista ContraPonto, Belo Horizonte, v.5, n.7, 2º sem. 2015, p. 92-104.

Verhoeven, M. Die Weiße Rose. [Filme] Produção de Sentana; CCC- Filmkunst; Hessischer Rundfunk, direção e roteiro de Michael Verhoeven. Alemanha: TeleCulture, 1982. 1 DVD, 123 min. color. son.

VielHABER, K.; HANISCH, H.; KNOOP-GRAF, A. Gewalt und Gewissen. Willi Graf und die "Weiße Rose". Würzburg: Echter-Verlag, 1963.

ZARUSKY, J. Widerstand als Hochverrat: 1933-1945. Eine mikrofiche-Edition des Instituts für Zeitgeschichte. In: Vierteljahrshefte für Zeitgeschichte. Oldenbourg Wissenschaftsverlag, out. 1994, pp. 671-678.

Resumo: O objetivo deste artigo é apresentar um estudo preparatório para a tradução (alemão-português) de fragmentos dos depoimentos de Franz Müller e Hans Hirzel, ex-integrantes do grupo de resistência alemã Rosa Branca, em 1984 no Parlamento Alemão. Baseando-nos no conceito-chave de Unrecht (Stolleis, 1994) como expressão da injustiça praticada pelo nazismo em oposição a um conceito de justiça como expressão de um direito considerado verdadeiro, encontramos nesses fragmentos o cerne da discussão acerca da validade do direito e das práticas jurídicas durante o nazismo.

Palavras-chave: Injustiça, Nazismo, Direito, História, Tradução. 


\begin{abstract}
The aim of this article is to present a preparatory study for the translation (German-Brazilian Portuguese) of fragments from statements made by Franz Müller and Hans Hirzel, ex-members of the German resistance group The White Rose, that took place at the German Bundestag in Berlin in 1984. Based on the key concept of Unrecht (Stolleis, 1994) as expression of the injustice practiced by the Nazism in opposition to a justice concept as expression of a law considered as true, we find in these fragments the heart of the discussion about the validity of the law and the legal practices in the Nazism.
\end{abstract}

Keywords: Injustice, Nazism, Right, History, Translation 